\title{
Executive summary of the Stages of Reproductive Aging Workshop + 10: addressing the unfinished agenda of staging reproductive aging
}

\author{
Siobán D. Harlow, PhD ${ }^{1}$, Margery Gass, MD, NCMP ${ }^{2}$, Janet E. Hall, MD ${ }^{3}$, Roger Lobo, MD ${ }^{4}$, \\ Pauline Maki, PhD ${ }^{5}$, Robert W. Rebar, MD ${ }^{6}$, Sherry Sherman, PhD ${ }^{7}$, Patrick M. Sluss, PhD $^{8}$, \\ and Tobie J. de Villiers, MBChB, FRCOG, FCOG (SA) ${ }^{9}$ For the STRAW + 10 Collaborative \\ Group \\ ${ }^{1}$ Department of Epidemiology, University of Michigan; Ann Arbor, MI \\ ${ }^{2}$ The North American Menopause Society; Mayfield Heights, $\mathrm{OH}$ \\ ${ }^{3}$ The Endocrine Society; Department of Medicine, Harvard Medical School; Boston, MA \\ ${ }^{4}$ Department of Obstetrics and Gynecology, Columbia University; New York, NY \\ ${ }^{5}$ Department of Psychiatry and Psychology, University of Illinois; Chicago, IL \\ ${ }^{6}$ American Society for Reproductive Medicine; Birmingham, AL \\ ${ }^{7}$ National Institute of Aging; Bethesda, MD \\ ${ }^{8}$ Department of Pathology, Harvard Medical School; Boston, MA \\ ${ }^{9}$ International Menopause Society; Cape Town, South Africa
}

\begin{abstract}
Objective-The aim of this article is to summarize the recommended updates to the 2001 Stages of Reproductive Aging Workshop (STRAW) criteria. The 2011 STRAW + 10 reviewed advances in understanding of the critical changes in hypothalamic-pituitary-ovarian function that occur before and after the final menstrual period.

Methods-Scientists from five countries and multiple disciplines evaluated data from cohort studies of midlife women and in the context of chronic illness and endocrine disorders on change in menstrual, endocrine, and ovarian markers of reproductive aging including antimüllerian
\end{abstract}

\footnotetext{
Correspondence and reprints to: Siobán D. Harlow, PhD, Department of Epidemiology, University of Michigan 1415 Washington Heights, Ann Arbor MI 48109. harlow@umich.edu.

This article is solely the responsibility of the authors and does not necessarily represent the official views of the NIA, ORWH, or NIH Financial disclosure/conflicts of interest: P.M.S. and S.S. declare no conflict of interest. M.G. receives salary support from The North American Menopause Society (NAMS). S.D.H. has grant support from the National Institute on Aging (NIA) and Eunice Kennedy Shriver National Institute of Child Health and Human Development (NICHD) and receives travel support from NAMS. J.E.H. has grant support from NIA and receives travel support from the Endocrine Society. R.L. is past president of the American Society for Reproductive Medicine (ASRM). P.M. receives grant support from the National Institute on Mental Health (NIMH), the NIA, the National Institute of Allergy and Infectious Diseases (NIAID), and the National Institute on Drug Abuse (NIDA); is on the Board of Trustees for NAMS; and has previously consulted for Noven Pharmaceuticals, received lecture fees from the Royal Ottawa Foundation for Mental Health, the Mayo Clinic, Baycrest, and Northwestern University and received travel support from the Society for Women's Health Research, the International Menopause Society, Pfizer, the Australasian Pacific Menopause Society, Virginia Commonwealth University Institute for Women's Health. R.W.R. receives salary support from ASRM. T.J.d.V. declares no direct conflict of interest as regards the submitted article but has in the past received consultancy fees from Adcock Ingram and Pfizer; speaker's fees from Servier; and travel support from Amgen, Pfizer, and Bayer.
} 
hormone, inhibin-B, follicle-stimulating hormone, and antral follicle count. Modifications were adopted by consensus.

Results-STRAW + 10 simplified bleeding criteria for the early and late menopausal transition, recommended modifications to criteria for the late reproductive stage (Stage -3 ) and the early postmenopause stage (Stage +1 ), provided information on the duration of the late transition (Stage-1) and early postmenopause (Stage +1 ), and recommended application regardless of women's age, ethnicity, body size, or lifestyle characteristics.

Conclusions-STRAW +10 provides a more comprehensive basis for assessing reproductive aging in research and clinical contexts. Application of the STRAW + 10 staging system should improve comparability of studies of midlife women and facilitate clinical decision making. Nonetheless, important knowledge gaps persist, and seven research priorities are identified.

\section{Keywords}

Reproductive aging; Ovarian aging; Menopause; Follicle-stimulating hormone; Antimüllerian hormone; Antral follicle count; Inhibin-B

The 2001 Stages of Reproductive Aging Workshop (STRAW) proposed nomenclature and a staging system for ovarian aging including menstrual and qualitative hormonal criteria to define each stage. ${ }^{1-4}$ The STRAW staging system is widely considered the gold standard for characterizing reproductive aging through menopause, just as the Marshall-Tanner Stages characterize pubertal maturation. ${ }^{5}$ Research conducted during the past 10 years has advanced knowledge of the critical changes in hypothalamic-pituitary and ovarian function that occur before and after the final menstrual period. These advances were the topic of a follow-up workshop "STRAW + 10: Addressing the Unfinished Agenda of Staging Reproductive Aging” (STRAW + 10). STRAW + 10, held in Washington, DC, on September 20 and 21, 2011, reviewed these scientific advances and updated the STRAW criteria. The sponsors were the National Institute on Aging (NIA) and Office of Research on Women's Health (ORWH) of the National Institutes of Health, The North American Menopause Society (NAMS), the American Society for Reproductive Medicine (ASRM), the International Menopause Society (IMS), and the Endocrine Society. The STRAW + 10 workshop achieved the following aims:

1. to reevaluate criteria for the onset of late reproductive life and early menopausal transition, given new population-based data relating to follicle-stimulating hormone (FSH), antral follicle count (AFC), antimüllerian hormone (AMH), and inhibin-B;

2. to reevaluate criteria for staging postmenopause, given new population-based data on changes in FSH and estradiol concentrations after the final menstrual period (FMP);

3. to reevaluate applicability to women based on variations in body size, lifestyle characteristics, and health status; and

4. to identify remaining gaps in scientific knowledge and research priorities.

\section{BACKGROUND AND SIGNIFICANCE}

The menopausal transition marks a period of physiologic changes as women approach reproductive senescence. Evidence supports the clinical importance of the transition for many women as a period of temporal changes in health and quality of life (ie, vasomotor symptoms, sleep disturbance, depression) and longer-term changes in several health outcomes (ie, urogenital symptoms, bone, lipids) ${ }^{6-15}$ that may influence women's quality of life and the likelihood of healthy aging. As a standardized staging system for reproductive 
aging, STRAW made a substantial contribution to women's health research by providing consistent classification of menopause status for studies of midlife women. Importantly, STRAW facilitated research that aimed to distinguish the health effects of ovarian versus somatic aging. The STRAW staging system also serves as a clinical tool for women and their healthcare providers to guide the assessment of fertility, contraceptive needs, and healthcare decision making. ${ }^{16,17}$

Building upon previous consensus meetings of the World Health Organization and the Council of Affiliated Menopause Societies, ${ }^{18}$ STRAW reevaluated nomenclature, proposed a standardized staging system, and recommended criteria for defining the onset of each stage. STRAW participants evaluated potential criteria including menstrual cycles; endocrinologic parameters including FSH, estradiol, AMH, and inhibin-B; symptoms; fertility; and ovarian imaging including AFC. Of the candidate biomarkers considered in 2001, only FSH was consistently measurable in a clinical setting. Data were insufficient to define quantitative criteria for FSH or to clarify the precise timing of change in FSH levels. Information on AFC and on the relationship among AMH, inhibin-B, and the timing of ovarian aging was limited. Symptoms were considered to be subjective and acknowledged not to be universally experienced. STRAW therefore restricted staging recommendations to menstrual cycle bleeding criteria and qualitative FSH criteria.

\section{Seven Stages of the 2001 STRAW Staging System}

STRAW divided the adult female life into three broad phases: reproductive, the menopausal transition, and postmenopause. These three phases included a total of seven stages centered on the FMP (Stage 0$).{ }^{1-4}$ The reproductive phase was divided into Stages $-5,-4$, and -3 corresponding to early, peak, and late, respectively. The menopausal transition phase consisted of Stage -2 (early) and Stage -1 (late), and the postmenopause phase contained Stages +1 (early) and +2 (late). Stage- 3 was characterized by regular menstrual cycles and increasing levels of FSH. Stage -2 was characterized by variability in menstrual cycle length and increased levels of FSH. Stage -1 was characterized by onset of skipped cycles or amenorrhea of at least 60 days and continued elevation of FSH.

\section{The ReSTAGE Collaboration}

The ReSTAGE Collaboration subsequently conducted empirical analyses to assess the validity and reliability of the 2001 STRAW's original menstrual cycle criteria in four cohort studies-the TREMIN study, the Melbourne Women's Midlife Health Project, the Seattle Midlife Women's Health Study, and the Study of Women's Health Across the Nation (SWAN). Findings supported STRAW's recommendations, provided more precise specification of menstrual criteria for early and late transition, and recommended a quantitative cutpoint for FSH levels characteristic of the late transition. ${ }^{19-22}$

\section{Generalizability}

A limitation of the original STRAW was its recommendation, based on the available evidence, that the staging system only be applied to healthy women. STRAW explicitly recommended against applying the criteria to seven subgroups of women, ${ }^{1-4}$ including smokers (19\% of US women aged 45-64 $\mathrm{y}^{23}$ ), women with a body mass index (BMI) greater than $30 \mathrm{~kg} / \mathrm{m}^{2}$ (38\% of US women ${ }^{24}$ ), and women who had undergone hysterectomy $\left(35 \%\right.$ of US women ${ }^{25}$ ). Women engaged in heavy aerobic exercise and women with chronic menstrual cycle irregularities, uterine abnormalities or ovarian abnormalities, or significant illness such as cancer were also excluded. Another limitation of the 2001 STRAW was the lack of insight regarding the applicability of the staging system in diverse populations. In 2001, few data were available from studies of multiethnic or diverse socioeconomic populations. Recent data from multiethnic cohorts now permit the assessment of 
generalizability, ${ }^{17,22,26-33}$ although data from low-resource countries remain quite limited. ${ }^{34,35}$

STRAW had a sustained influence on research in the field, prompting the assessment of trajectories of change in endocrine levels and biomarkers of ovarian senescence as well as the evaluation of how these trajectories vary by body size, smoking, ethnicity, and other factors. ${ }^{26-33,36-55}$ Ten years later, the understanding of ovarian aging and its endocrine and clinical correlates has advanced considerably, providing a more nuanced and comprehensive understanding of the critical junctures that occur during reproductive aging before and after the FMP. For example, Fig. 1 illustrates changes in mean FSH and estradiol concentrations in relation to time before and after the FMP in the SWAN cohort. ${ }^{22}$ The role of AMH and inhibin-B as markers of declining fertility and ovarian aging is more clearly understood, as are the relationships among patterns of decline in $\mathrm{AMH}$, inhibin-B, AFC, and primordial follicle counts. $26,37,38,42,43,45-48,51,53,56-58$ The goal of the STRAW + 10 was to review significant advances in the field and develop recommendations for updating the original STRAW criteria.

\section{METHODS}

STRAW + 10 involved a 2-day in-person meeting hosted at the 2011 Annual Meeting of NAMS. On the first day, international experts gave oral presentations reviewing recent data bearing on the goals, as part of a public symposium, followed by comments and discussion from the audience. The first two sessions focused on data from prospective cohort studies of midlife women; clinical findings related to changes in patterns and levels of menstrual, endocrine, and ovarian markers of reproductive aging; and data relevant to how these trajectories vary by ethnicity, body size, and smoking status. A particular focus was on patterns of change in AMH, inhibin-B, FSH, estradiol, and AFC and their interrelationships. A third session focused on emerging evidence related to staging reproductive aging in the context of cancer treatment, chronic illness including cancer and human immunodeficiency virus (HIV)-acquired immunodeficiency syndrome (AIDS), and endocrine disorders including polycystic ovarian syndrome (PCOS) and primary ovarian insufficiency (POI, otherwise known as premature ovarian failure). At the end of day 1, a panel reviewed and the participants discussed modifications that had been proposed by symposium speakers. STRAW +10 explicitly considered the feasibility of applying criteria in low-resource countries.

Subsequently, 41 scientists convened to develop consensus and propose modifications to the STRAW staging system. These participants had clinical and/or research experience in female reproductive aging and included scientists from several key research groups in the United States, Canada, Australia, the Netherlands, and South Africa, as well as representatives from National Institutes of Health-funded cohort studies of midlife women that have biologic samples ${ }^{59}$ including the SWAN, Michigan Bone Health and Metabolism Study, Seattle Midlife Women's Health Study, Biodemographic Models of Reproductive Aging, and the Penn Ovarian Aging Study as well as the Australian Melbourne Women's Midlife Health Project and junior investigators who submitted qualifying posters.

Three breakout groups were formed based on scientific expertise and interest. Group 1 reviewed criteria for STRAW Stages -4 to -2 . Group 2 reviewed criteria for STRAW Stages -1 to +2 . Each of these two groups was subdivided into two subgroups and assigned a rapporteur. Each subgroup proposed modifications to the STRAW paradigm separately, considering criteria for the relevant stages in healthy women and the weight of evidence concerning the appropriateness of applying these criteria to smokers and women regardless of body size. Each subgroup then reviewed the recommendations of the other subgroup and 
discussed points of disagreement until consensus was reached. Group 3 discussed staging in the context of endocrine disorders and chronic illness and proposed modifications.

On the second day, the scientists reconvened to review and discuss proposed modifications to the STRAW staging system. First, Group 1 and Group 2 reviewed the other group's recommendations. In this way, all groups reviewed all stages under consideration (Stages -4 to +2 ). Afterward, the group-at-large met to discuss each proposal, and final recommendations were adopted by consensus. Points of disagreement were discussed until consensus was achieved on common principles. In general, disagreements reflected points for which data was not yet adequate to make a recommendation. Preliminary recommendations of the STRAW + 10 were presented at the NAMS annual meeting on September 22, with comments and requests for clarification considered by the STRAW +10 program committee.

\section{RESULTS}

STRAW + 10 retained the criteria for an ideal staging system used by the 2001 Workshop. Therefore, a staging system should

1 rely primarily on objective data;

2 use widely available, reliable, noninvasive, and inexpensive tests;

3 allow for prospective classification of women; and

4 permit unambiguous classification of women into a unique stage.

In addition, it was concluded that the modified staging system should

5 retain the same widely accepted nomenclature;

6 consider menstrual cycle criteria to remain the most important criteria given the continuing lack of international standardization of biomarker assays as well as their cost and/or invasiveness, particularly in the context of resource-poor countries;

$7 \quad$ consider biomarker criteria as supportive criteria given the lack of assay standardization (supportive criteria are to be used only as necessary and should not be interpreted as required for diagnosis); and

8 use criteria that are independent of age, symptoms, and pathology (because no universal menopausal syndrome has been established across ethnic groups, ${ }^{60}$ two key symptoms are incorporated only as descriptive additional information that may support other criteria in assessing stage ${ }^{61}$ ).

The revised STRAW +10 Staging System is presented in Fig. 2. STRAW + 10 recommended the acceptance of the ReSTAGE Collaboration's more precise and simplified specification of the menstrual cycle criteria for the early and late menopausal transition and concurred with ReSTAGE recommendations that the quantification of the FSH criteria in Stage -1 is possible given the improved standardization of this assay and additional population-based data. In addition, STRAW + 10 recommended modifications to the criteria for the late reproductive stage (Stage -3) as well as the early postmenopause stage (Stage +1 ) and provided information on the duration of the late transition (Stage -1) and early postmenopause (Stage +1 ) stages. Although additional biomarkers, especially AMH and $\mathrm{AFC}$, have considerable promise, the lack of standardized assays and data from noninfertility populations remain important limitations to their incorporation into the STRAW staging system and their utility as clinical tools for staging reproductive aging. Nonetheless, the revised STRAW + 10 Staging System includes qualitative criteria for these 
biomarkers during the late reproductive life when relative changes in these parameters have important consequences for fertility potential.

The definition and rationale for key revisions to the staging criteria include the following:

Late reproductive stage (Stage -3) - The late reproductive stage marks the time when fecundability begins to decline and during which a woman may begin to notice changes in her menstrual cycles. Given that critical endocrine parameters begin to change before overt changes in menstrual cyclicity and that these endocrine changes are important to fertility assessments, STRAW +10 recommended that the late reproductive stage be subdivided into two substages ( $-3 b$ and $-3 a)$. In Stage $-3 b$, menstrual cycles remain regular without change in length or early follicular phase FSH levels; however, AMH and antral follicle counts are low. Most ${ }^{53,62}$ but not all ${ }^{63}$ studies suggest that inhibin-B is also low. In Stage $-3 a$, subtle changes in menstrual cycle characteristics, specifically shorter cycles, ${ }^{64-66}$ begin. Early follicular phase (cycle days 2-5) FSH increases and becomes more variable, with the other three markers of ovarian aging being low. The lack of standardized AMH assays prevented the development of quantitative recommendations for this biomarker.

Early menopausal transition (Stage-2)-Early menopausal transition is marked by increased variability in menstrual cycle length, defined as a persistent difference of 7 days or more in the length of consecutive cycles. Persistence is defined as recurrence within 10 cycles of the first variable length cycle. Cycles in the early menopausal transition are also characterized by elevated but variable early follicular phase FSH levels and low AMH levels and AFC.

Late menopausal transition (Stage -1)-The late menopausal transition is marked by the occurrence of amenorrhea of 60 days or longer. Menstrual cycles in the late menopausal transition are characterized by increased variability in cycle length, extreme fluctuations in hormonal levels, and increased prevalence of anovulation. In this stage, FSH levels are sometimes elevated into the menopausal range and sometimes within the range characteristic of the earlier reproductive years, particularly in association with high estradiol levels. The development of international standards and the availability of substantive population-based data now permit the definition of quantitative FSH criteria, with levels greater than $25 \mathrm{IU} / \mathrm{L}$ in a random blood draw characteristic of being in late transition, based on current international pituitary standards that approximate more than $40 \mathrm{IU} / \mathrm{L}$ in the previously used urine-based gonadotropin standards ${ }^{67-69}$ Empirical analyses should be undertaken to confirm this recommendation, and researchers and clinicians should carefully evaluate the appropriate FSH value, depending on the assay they use. Based on studies of menstrual calendars and on changes in FSH and estradiol, this stage is estimated to last, on average, 1 to 3 years. Symptoms, most notably vasomotor symptoms, are likely to occur during this stage.

Early postmenopause (Stage $\mathbf{+ 1 a}, \mathbf{+ 1 b}, \mathbf{+ 1 c}$ )-New data on the trajectories of change in mean levels of FSH and estradiol $22,30,32,40,41,52,54,55$ indicate that FSH continues to increase and that estradiol continues to decrease until approximately 2 years after the FMP, after which the levels of each of these hormones stabilize. Therefore, STRAW +10 recommended that early postmenopause be subdivided into three substages $(+1 \mathrm{a},+1 \mathrm{~b}$, and $+1 \mathrm{c})$.

Stages $+1 \mathrm{a}$ and $+1 \mathrm{~b}$ each last 1 year and end at the time point at which FSH and estradiol levels stabilize. Stage +1 a marks the end of the 12-month period of amenorrhea required to define that the FMP has occurred. It corresponds to the end of "perimenopause," a term still 
in common usage that means the time around menopause and begins at Stage -2 and ends 12 months after the FMP. Stage $+1 b$ includes the remainder of the period of rapid changes in mean FSH and estradiol levels. Based on studies of hormonal changes, Stages $+1 \mathrm{a}$ and $+1 \mathrm{~b}$ together are estimated to last, on average, 2 years. Symptoms, most notably vasomotor symptoms, are most likely to occur during this stage.

Stage $+1 \mathrm{c}$ represents the period of stabilization of high FSH levels and low estradiol values that is estimated to last 3 to 6 years; therefore, the entire early postmenopause lasts approximately 5 to 8 years. Further specification of this stage will require additional studies of trajectories of change in FSH and estradiol from the FMP through the late postmenopause.

Late postmenopause (Stage $+\mathbf{2})$-Stage +2 represents the period in which further changes in reproductive endocrine function are more limited and processes of somatic aging become of paramount concern. Symptoms of vaginal dryness and urogenital atrophy become increasingly prevalent at this time. ${ }^{7,70-72}$ However, many years after menopause, it has been observed that there may be a further decline in levels of FSH in very old persons ${ }^{73,74}$; future studies will be needed to determine whether an additional stage is warranted near the end of life.

\section{Inclusiveness of the STRAW + 10 criteria}

Evidence now supports the applicability of the STRAW +10 recommendations for most women. Epidemiologic and clinical studies have documented that the process of reproductive aging, although influenced by demographic factors, lifestyle, and BMI, follows a robust and predictable pattern. ${ }^{22,26,27,32,33,41,75}$ Although smoking and BMI influence hormonal levels and the timing of transition, these factors do not alter the trajectory of change in bleeding patterns or hormonal levels with reproductive aging. Therefore, the STRAW + 10 staging system is applicable to women regardless of age, demographic, BMI, or lifestyle characteristics.

The STRAW + 10 model does not use age as a criterion for determining reproductive staging. However, women meeting the criteria for POI/premature ovarian failure (age $<40 \mathrm{y}$ with 4 mo of amenorrhea and two serum FSH levels [at least a month apart] in the menopausal range) do not easily fit into this model. The course of reproductive aging in women with POI/premature ovarian failure seems to be considerably more variable than that of women with normal reproductive aging. Not only are there several potential etiologies but also a substantial proportion of women have spontaneous resumption of menstrual function once the diagnosis has been confirmed, including ovulation and successful spontaneous pregnancy. ${ }^{76}$ Additional research is needed to better document the process of ovarian aging in these women and whether the course of ovarian aging differs by etiology of POI. Studies of reproductive aging in POI are considered to be a research priority.

\section{Hysterectomy and endometrial ablation}

Women who have undergone hysterectomy or endometrial ablation cannot be staged by menstrual bleeding criteria. ${ }^{77}$ Reproductive stage in these women can only be assessed using the supportive criteria, that is, the endocrine markers of ovarian aging. It is recommended that clinicians and researchers wait at least 3 months after surgery to assess endocrine status, given emerging evidence that pelvic surgeries may transiently raise FSH levels. ${ }^{78-81}$ Further research on the nature and duration of alterations in biomarkers of ovarian aging secondary to pelvic surgery is warranted. In most cases, staging will be limited to the classification of whether such women are premenopausal or postmenopausal. A single sample for 
measurement of FSH and estradiol may be ambiguous or misleading, and at least one repeated measurement is often required.

\section{Polycystic ovarian syndrome}

Women with PCOS frequently experience oligomenorrhea that is not attributable to ovarian aging. Therefore, the current menstrual cycle criteria used to stage reproductive aging are not applicable to this population. Understanding of the changes occurring before menopause in this group of women is limited. Some data suggest that women with PCOS may experience a later age at menopause, ${ }^{48,82}$ as well as more regular cycles with reproductive aging ${ }^{83,84}$; however, the experience of reproductive aging in PCOS is not well understood. Similarly, menstrual cycle criteria are not applicable in women with hypothalamic amenorrhea. Studies of reproductive aging in these subgroups of women are considered to be a research priority.

\section{Women with chronic illness undergoing chemotherapy}

Many medications and loss of body fat can cause amenorrhea, which can make the staging of the menopausal transition difficult. Several important subgroups remain difficult to stage yet deserve attention in any staging system. ${ }^{38,56,85-88}$ Depending on the age at treatment and cancer treatment type, a significant proportion of women who undergo cancer treatment, particularly with alkylating agents, may experience transient increases in FSH and decreases in AMH and AFC with return of bleeding even after 12 months or more of amenorrhea. ${ }^{38,56,87-89}$ In these women, resumption of menstrual cycles may not indicate a return of normal menstrual function. Women undergoing treatment with tamoxifen pose an additional problem because FSH and estradiol levels may be altered by this treatment and may therefore be misleading and cause abnormal bleeding. ${ }^{90}$ Women with chronic illnesses such as HIV-AIDS also pose a problem in the staging of reproductive aging because of the lack of reliability of bleeding patterns and hormonal markers. ${ }^{85,86}$ Staging in these women will require assessment with menstrual cycle criteria, the supportive criteria using relevant biomarkers, and age to better characterize their ovarian function. Large prospective cohort studies are needed to better characterize the trajectories of ovarian aging in these populations.

\section{CONCLUSIONS AND RESEARCH PRIORITIES}

STRAW + 10 revised and extended the STRAW recommendations to include additional criteria for defining specific stages of reproductive life. The revised staging system provides a more comprehensive basis for classification and assessment, from the late reproductive stage through the menopausal transition and into postmenopause. Its application should improve comparability of studies of midlife women by establishing clear criteria for ascertaining women's reproductive stage. The STRAW +10 recommendations are expected to improve guidance for classifying the ovarian status of midlife women in the research setting while advancing efforts to translate this new science for clinicians and women.

Although scientific understanding of ovarian aging has advanced considerably in the last decade, important gaps in scientific knowledge persist. The workshop participants identified seven research priorities.

1. Lack of standardized assays for key biomarkers remains an important limitation in efforts to stage reproductive aging and to translate research findings to costeffective clinical tools. Given the importance of AMH in relation to fertility and its relative stability across the menstrual cycle, the development of an international standard for the assessment of AMH is of paramount importance. 
2. Empirical analysis across multiple cohorts is needed to specify precise menstrual cycle criteria for Stages $-3 b$ and $-3 a$.

3. Studies are needed to characterize the hormonal changes of postmenopause from Stage +1 to +2 because data across these stages are limited; several cohort studies are well positioned to provide this information. The development of highly sensitive, well characterized assays is needed.

4. Given that the large cohort studies of midlife women were initiated before the STRAW staging system was developed, these cohorts should be supported to apply the STRAW + 10 staging criteria to reanalyze key findings on the clinical changes that occur across the menopausal transition.

5. Improved characterization of the pattern, timing, and level of reproductive biomarkers across nations is necessary, especially to provide data on the experience of women from low-resource countries.

6. Research is needed to better understand the process of reproductive aging and appropriate staging criteria for women with PCOS and POI and those who have had removal of a single ovary and/or hysterectomy.

7. Research is needed to better evaluate staging in women with chronic illness such as HIV infection and those undergoing cancer treatment.

\section{Acknowledgments}

Funding/support: The Stages of Reproductive Aging Workshop (STRAW) + 10 had grant support from the National Institutes of Health (NIH), Department of Health and Human Services (DHHS), through the National Institute on Aging (NIA) (AG039961), and the NIH Office of Research on Women's Health (ORWH) as well as from The North American Menopause Society (NAMS), the American Society for Reproductive Medicine (ASRM), the International Menopause Society (IMS), and the Endocrine Society.

STRAW + 10 In Memoriam: MaryFran Sowers, PhD, University of Michigan.

\section{References}

1. Soules MR, Sherman S, Parrott E, et al. Executive summary: Stages of Reproductive Aging Workshop (STRAW). Climacteric. 2001; 4:267-272. [PubMed: 11770182]

2. Soules MR, Sherman S, Parrott E, et al. Stages of Reproductive Aging Workshop (STRAW). J Womens Health Gend Based Med. 2001; 10:843-848. [PubMed: 11747678]

3. Soules MR, Sherman S, Parrott E, et al. Executive summary: Stages of Reproductive Aging Workshop (STRAW). Fertil Steril. 2001; 76:874-878. [PubMed: 11704104]

4. Soules MR, Sherman S, Parrott E, et al. Executive summary: Stages of Reproductive Aging Workshop (STRAW) Park City, Utah, July, 2001. Menopause. 2001; 8:402-407. [PubMed: 21141649]

5. Marshall WA, Tanner JM. Variations in pattern of pubertal changes in girls. Arch Dis Child. 1969; 44:291-303. [PubMed: 5785179]

6. Bromberger JT, Schott LL, Kravitz HM, et al. Longitudinal change in reproductive hormones and depressive symptoms across the menopausal transition: results from the Study of Women's Health Across the Nation (SWAN). Arch Gen Psychiatry. 2010; 67:598-607. [PubMed: 20530009]

7. Dennerstein L, Dudley EC, Hopper JL, Guthrie JR, Burger HG. A prospective population-based study of menopausal symptoms. Obstet Gynecol. 2000; 96:351-358. [PubMed: 10960625]

8. Freeman EW, Grisso JA, Berlin J, Sammel M, Garcia-Espana B, Hollander L. Symptom reports from a cohort of African American and white women in the late reproductive years. Menopause. 2001; 8:33-42. [PubMed: 11201513] 
9. Hollander LE, Freeman EW, Sammel MD, Berlin JA, Grisso JA, Battistini M. Sleep quality, estradiol levels, and behavioral factors in late reproductive age women. Obstet Gynecol. 2001; 98:391-397. [PubMed: 11530118]

10. Lee CG, Carr MC, Murdoch SJ, et al. Adipokines, inflammation, and visceral adiposity across the menopausal transition: a prospective study. J Clin Endocrinol Metab. 2009; 94:1104-1110. [PubMed: 19126626]

11. Maki PM, Freeman EW, Greendale GA, et al. Summary of the National Institute on Agingsponsored conference on depressive symptoms and cognitive complaints in the menopausal transition. Menopause. 2010; 17:815-822. [PubMed: 20616668]

12. Matthews KA, Crawford SL, Chae CU, et al. Are changes in cardiovascular disease risk factors in midlife women due to chronological aging or to the menopausal transition? J Am Coll Cardiol. 2009; 54:2366-2373. [PubMed: 20082925]

13. Neer RM. Bone loss across the menopausal transition. Ann N Y Acad Sci. 2010; 1192:66-71. [PubMed: 20392219]

14. Sowers MR, Jannausch M, McConnell D, et al. Hormone predictors of bone mineral density changes during the menopausal transition. J Clin Endocrinol Metab. 2006; 91:1261-1267. [PubMed: 16403818]

15. Woods NF, Mitchell ES. Sleep symptoms during the menopausal transition and early postmenopause: observations from the Seattle Midlife Women's Health Study. Sleep. 2010; 33:539-549. [PubMed: 20394324]

16. Bastian LA, Smith CM, Nanda K. Is this woman perimenopausal? JAMA. 2003; 289:895-902. [PubMed: 12588275]

17. Santoro N, Brockwell S, Johnston J, et al. Helping midlife women predict the onset of the final menses: SWAN, the Study of Women's Health Across the Nation. Menopause. 2007; 14:415-424. [PubMed: 17303963]

18. Utian WH. Menopause-related definitions. Int Congress Series. 2004; 1266:133-138.

19. Harlow SD, Cain K, Crawford S, et al. Evaluation of four proposed bleeding criteria for the onset of late menopausal transition. J Clin Endocrinol Metab. 2006; 91:3432-3438. [PubMed: 16772350]

20. Harlow SD, Crawford S, Dennerstein L, Burger HG, Mitchell ES, Sowers MF. Recommendations from a multi-study evaluation of proposed criteria for staging reproductive aging. Climacteric. 2007; 10:112-119. [PubMed: 17453859]

21. Harlow SD, Mitchell ES, Crawford S, Nan B, Little R, Taffe J. The ReSTAGE Collaboration: defining optimal bleeding criteria for onset of early menopausal transition. Fertil Steril. 2008; 89:129-140. [PubMed: 17681300]

22. Randolph JF Jr, Zheng H, Sowers MR, et al. Change in follicle-stimulating hormone and estradiol across the menopausal transition: effect of age at the final menstrual period. J Clin Endocrinol Metab. 2011; 96:746-754. [PubMed: 21159842]

23. Vital signs: current cigarette smoking among adults aged >or $=18$ years—United States. MMWR Morb Mortal Wkly Rep. 2009; 59:1135-1140.

24. Flegal KM, Carroll MD, Ogden CL, Curtin LR. Prevalence and trends in obesity among US adults, 1999-2008. JAMA. 2010; 303:235-241. [PubMed: 20071471]

25. Merrill RM, Layman AB, Oderda G, Asche C. Risk estimates of hysterectomy and selected conditions commonly treated with hysterectomy. Ann Epidemiol. 2008; 18:253-260. [PubMed: 18280923]

26. Freeman EW, Gracia CR, Sammel MD, Lin H, Lim LC, Strauss JF III. Association of antimullerian hormone levels with obesity in late reproductive-age women. Fertil Steril. 2007; 87:101-106. [PubMed: 17109858]

27. Gracia CR, Freeman EW, Sammel MD, Lin H, Nelson DB. The relationship between obesity and race on inhibin $\mathrm{B}$ during the menopause transition. Menopause. 2005; 12:559-566. [PubMed: 16145310]

28. Huddleston HG, Cedars MI, Sohn SH, Giudice LC, Fujimoto VY. Racial and ethnic disparities in reproductive endocrinology and infertility. Am J Obstet Gynecol. 2010; 202:413-419. [PubMed: 20207341] 
29. Manson JM, Sammel MD, Freeman EW, Grisso JA. Racial differences in sex hormone levels in women approaching the transition to menopause. Fertil Steril. 2001; 75:297-304. [PubMed: 11172830]

30. Randolph JF Jr, Sowers M, Bondarenko IV, Harlow SD, Luborsky JL, Little RJ. Change in estradiol and follicle-stimulating hormone across the early menopausal transition: effects of ethnicity and age. J Clin Endocrinol Metab. 2004; 89:1555-1561. [PubMed: 15070912]

31. Randolph JF Jr, Sowers M, Gold EB, et al. Reproductive hormones in the early menopausal transition: relationship to ethnicity, body size, and menopausal status. J Clin Endocrinol Metab. 2003; 88:1516-1522. [PubMed: 12679432]

32. Sammel MD, Freeman EW, Liu Z, Lin H, Guo W. Factors that influence entry into stages of the menopausal transition. Menopause. 2009; 16:1218-1227. [PubMed: 19512950]

33. Su HI, Sammel MD, Freeman EW, Lin H, DeBlasis T, Gracia CR. Body size affects measures of ovarian reserve in late reproductive age women. Menopause. 2008; 15:857-861. [PubMed: 18427357]

34. Sievert LL, Begum K, Sharmeen T, Chowdhury O, Muttukrishna S, Bentley G. Patterns of occurrence and concordance between subjective and objective hot flashes among Muslim and Hindu women in Sylhet, Bangladesh. Am J Hum Biol. 2008; 20:598-604. [PubMed: 18461600]

35. Sievert LL, Saliba M, Reher D, et al. The medical management of menopause: a four-country comparison care in urban areas. Maturitas. 2008; 59:7-21. [PubMed: 18178044]

36. Battistini M, Freeman EW, Grisso JA, Sammel M, Hollander L, Garcia-Espana B. Pilot study of racial differences and longitudinal changes in inhibin B in the late reproductive years. Fertil Steril. 2002; 77:193-195. [PubMed: 11779617]

37. Broekmans FJ, Faddy MJ, Scheffer G, te Velde ER. Antral follicle counts are related to age at natural fertility loss and age at menopause. Menopause. 2004; 11:607-614. [PubMed: 15545788]

38. Broekmans FJ, Soules MR, Fauser BC. Ovarian aging: mechanisms and clinical consequences. Endocr Rev. 2009; 30:465-493. [PubMed: 19589949]

39. Burger HG, Hale GE, Dennerstein L, Robertson DM. Cycle and hormone changes during perimenopause: the key role of ovarian function. Menopause. 2008; 15:603-612. [PubMed: 18574431]

40. Burger HG, Hale GE, Robertson DM, Dennerstein L. A review of hormonal changes during the menopausal transition: focus on findings from the Melbourne Women's Midlife Health Project. Hum Reprod Update. 2007; 13:559-565. [PubMed: 17630397]

41. Freeman EW, Sammel MD, Lin H, Gracia CR. Obesity and reproductive hormone levels in the transition to menopause. Menopause. 2010; 17:718-726. [PubMed: 20216473]

42. Hale GE, Zhao X, Hughes CL, Burger HG, Robertson DM, Fraser IS. Endocrine features of menstrual cycles in middle and late reproductive age and the menopausal transition classified according to the Staging of Reproductive Aging Workshop (STRAW) staging system. J Clin Endocrinol Metab. 2007; 92:3060-3067. [PubMed: 17550960]

43. Hansen KR, Hodnett GM, Knowlton N, Craig LB. Correlation of ovarian reserve tests with histologically determined primordial follicle number. Fertil Steril. 2011; 95:170-175. [PubMed: 20522327]

44. Hansen KR, Morris JL, Thyer AC, Soules MR. Reproductive aging and variability in the ovarian antral follicle count: application in the clinical setting. Fertil Steril. 2003; 80:577-583. [PubMed: 12969701]

45. Klein NA, Houmard BS, Hansen KR, et al. Age-related analysis of inhibin A, inhibin B, and activin a relative to the intercycle monotropic follicle-stimulating hormone rise in normal ovulatory women. J Clin Endocrinol Metab. 2004; 89:2977-2981. [PubMed: 15181087]

46. Knauff EA, Eijkemans MJ, Lambalk CB, et al. Anti-Mullerian hormone, inhibin B, and antral follicle count in young women with ovarian failure. J Clin Endocrinol Metab. 2009; 94:786-792. [PubMed: 19066296]

47. La Marca A, Sighinolfi G, Radi D, et al. Anti-Mullerian hormone (AMH) as a predictive marker in assisted reproductive technology (ART). Hum Reprod Update. 2010; 16:113-130. [PubMed: 19793843] 
48. Mulders AG, Laven JS, Eijkemans MJ, de Jong FH, Themmen AP, Fauser BC. Changes in antiMullerian hormone serum concentrations over time suggest delayed ovarian ageing in normogonadotrophic anovulatory infertility. Hum Reprod. 2004; 19:2036-2042. [PubMed: 15217995]

49. O'Connor KA, Ferrell R, Brindle E, et al. Progesterone and ovulation across stages of the transition to menopause. Menopause. 2009; 16:1178-1187. [PubMed: 19568209]

50. O'Connor KA, Ferrell RJ, Brindle E, et al. Total and unopposed estrogen exposure across stages of the transition to menopause. Cancer Epidemiol Biomarkers Prev. 2009; 18:828-836. [PubMed: 19240232]

51. Robertson DM. Anti-Mullerian hormone as a marker of ovarian reserve: an update. Womens Health (Lond Engl). 2008; 4:137-141. [PubMed: 19072515]

52. Robertson DM, Hale GE, Jolley D, Fraser IS, Hughes CL, Burger HG. Interrelationships between ovarian and pituitary hormones in ovulatory menstrual cycles across reproductive age. J Clin Endocrinol Metab. 2009; 94:138-144. [PubMed: 18854393]

53. Sowers MR, Eyvazzadeh AD, McConnell D, et al. Anti-mullerian hormone and inhibin B in the definition of ovarian aging and the menopause transition. J Clin Endocrinol Metab. 2008; 93:3478-3483. [PubMed: 18593767]

54. Sowers MR, Zheng H, McConnell D, Nan B, Harlow S, Randolph JF Jr. Follicle stimulating hormone and its rate of change in defining menopause transition stages. J Clin Endocrinol Metab. 2008; 93:3958-3964. [PubMed: 18647816]

55. Sowers MR, Zheng H, McConnell D, Nan B, Harlow SD, Randolph JF Jr. Estradiol rates of change in relation to the final menstrual period in a population-based cohort of women. J Clin Endocrinol Metab. 2008; 93:3847-3852. [PubMed: 18647803]

56. Su HI, Sammel MD, Green J, et al. Antimullerian hormone and inhibin B are hormone measures of ovarian function in late reproductive-aged breast cancer survivors. Cancer. 2010; 116:592-599. [PubMed: 19918920]

57. van Disseldorp J, Faddy MJ, Themmen AP, et al. Relationship of serum antimullerian hormone concentration to age at menopause. J Clin Endocrinol Metab. 2008; 93:2129-2134. [PubMed: 18334591]

58. van Rooij IA, Broekmans FJ, Scheffer GJ, et al. Serum antimullerian hormone levels best reflect the reproductive decline with age in normal women with proven fertility: a longitudinal study. Fertil Steril. 2005; 83:979-987. [PubMed: 15820810]

59. Ferrell RJ, Sowers M. Longitudinal, epidemiologic studies of female reproductive aging. Ann N Y Acad Sci. 2010; 1204:188-197. [PubMed: 20738290]

60. Avis NE, Brockwell S, Randolph JF Jr, et al. Longitudinal changes in sexual functioning as women transition through menopause: results from the Study of Women's Health Across the Nation. Menopause. 2009; 16:442-452. [PubMed: 19212271]

61. Avis NE, Zhao X, Johannes CB, Ory M, Brockwell S, Greendale GA. Correlates of sexual function among multi-ethnic middle-aged women: results from the Study of Women's Health Across the Nation (SWAN). Menopause. 2005; 12:385-398. [PubMed: 16037753]

62. Welt CK, McNicholl DJ, Taylor AE, Hall JE. Female reproductive aging is marked by decreased secretion of dimeric inhibin. J Clin Endocrinol Metab. 1999; 84:105-111. [PubMed: 9920069]

63. Robertson DM, Hale GE, Fraser IS, Hughes CL, Burger HG. A proposed classification system for menstrual cycles in the menopause transition based on changes in serum hormone profiles. Menopause. 2008; 15:1139-1144. [PubMed: 18779761]

64. Johannes CB, Crawford SL, Longcope C, McKinlay SM. Bleeding patterns and changes in the perimenopause: a longitudinal characterization of menstrual cycles. Clin Consult Obstet Gyncecol. 1996; 8:9-20.

65. Mitchell ES, Woods NF, Mariella A. Three stages of the menopausal transition from the Seattle Midlife Women's Health Study: toward a more precise definition. Menopause. 2000; 7:334-349. [PubMed: 10993033]

66. Van Voorhis BJ, Santoro N, Harlow S, Crawford SL, Randolph J. The relationship of bleeding patterns to daily reproductive hormones in women approaching menopause. Obstet Gynecol. 2008; 112:101-108. [PubMed: 18591314] 
67. Roche Diagnostics. Package Insert: Elecsys and cobas analyzers 2006-11. Vol. 13. Roche Diagnostics; Indianapolis, IN: FSH, Follicle Stimulating Hormone.

68. Abbott Laboratories. FSH. Package Insert: Architect Analyzers; 6C24, 34-4680/R1. 2007-10.

69. Stricker R, Eberhart R, Chevailler MC, Quinn FA, Bischof P. Establishment of detailed reference values for luteinizing hormone, follicle stimulating hormone, estradiol, and progesterone during different phases of the menstrual cycle on the Abbott ARCHITECT analyzer. Clin Chem Lab Med. 2006; 44:883-887. [PubMed: 16776638]

70. Dennerstein L, Dudley E, Burger H. Are changes in sexual functioning during midlife due to aging or menopause? Fertil Steril. 2001; 76:456-460. [PubMed: 11532464]

71. Stiles M, Redmer J, Paddock E, Schrager S. Gynecologic issues in geriatric women. J Womens Health (Larchmt). 2012; 21:4-9. [PubMed: 21999360]

72. Woods NF, Mitchell ES. Symptoms during the perimenopause: prevalence, severity, trajectory, and significance in women's lives. Am J Med. 2005; 118:14-24. [PubMed: 16414323]

73. Hall JE. Neuroendocrine physiology of the early and late menopause. Endocrinol Metab Clin North Am. 2004; 33:637-659. [PubMed: 15501638]

74. Hall JE, Lavoie HB, Marsh EE, Martin KA. Decrease in gonadotropin-releasing hormone (GnRH) pulse frequency with aging in postmenopausal women. J Clin Endocrinol Metab. 2000; 85:17941800. [PubMed: 10843154]

75. Schmitz KH, Lin H, Sammel MD, et al. Association of physical activity with reproductive hormones: the Penn Ovarian Aging Study. Cancer Epidemiol Biomarkers Prev. 2007; 16:20422047. [PubMed: 17905944]

76. Bidet M, Bachelot A, Bissauge E, et al. Resumption of ovarian function and pregnancies in 358 patients with premature ovarian failure. J Clin Endocrinol Metab. 2011; 96:3864-3872. [PubMed: 21994953]

77. Johnson BD, Merz CN, Braunstein GD, et al. Determination of menopausal status in women: the NHLBI-sponsored Women's Ischemia Syndrome Evaluation (WISE) Study. J Womens Health (Larchmt). 2004; 13:872-887. [PubMed: 15671703]

78. Gelbaya TA, Nardo LG, Fitzgerald CT, Horne G, Brison DR, Lieberman BA. Ovarian response to gonadotropins after laparoscopic salpingectomy or the division of fallopian tubes for hydrosalpinges. Fertil Steril. 2006; 85:1464-1468. [PubMed: 16580673]

79. Hehenkamp WJ, Volkers NA, Broekmans FJ, et al. Loss of ovarian reserve after uterine artery embolization: a randomized comparison with hysterectomy. Hum Reprod. 2007; 22:1996-2005. [PubMed: 17582145]

80. Qu X, Cheng Z, Yang W, Xu L, Dai H, Hu L. Controlled clinical trial assessing the effect of laparoscopic uterine arterial occlusion on ovarian reserve. J Minim Invasive Gynecol. 2010; 17:47-52. [PubMed: 20129332]

81. Sezik M, Ozkaya O, Demir F, Sezik HT, Kaya H. Total salpingectomy during abdominal hysterectomy: effects on ovarian reserve and ovarian stromal blood flow. J Obstet Gynaecol Res. 2007; 33:863-869. [PubMed: 18001455]

82. Dahlgren E, Johansson S, Lindstedt G, et al. Women with polycystic ovary syndrome wedge resected in 1956 to 1965: a long-term follow-up focusing on natural history and circulating hormones. Fertil Steril. 1992; 57:505-513. [PubMed: 1740195]

83. Elting MW, Korsen TJ, Rekers-Mombarg LT, Schoemaker J. Women with polycystic ovary syndrome gain regular menstrual cycles when ageing. Hum Reprod. 2000; 15:24-28. [PubMed: 10611183]

84. Elting MW, Kwee J, Korsen TJ, Rekers-Mombarg LT, Schoemaker J. Aging women with polycystic ovary syndrome who achieve regular menstrual cycles have a smaller follicle cohort than those who continue to have irregular cycles. Fertil Steril. 2003; 79:1154-1160. [PubMed: 12738511]

85. Santoro N, Arnsten JH, Buono D, Howard AA, Schoenbaum EE. Impact of street drug use, HIV infection, and highly active antiretroviral therapy on reproductive hormones in middle-aged women. J Womens Health (Larchmt). 2005; 14:898-905. [PubMed: 16372891]

86. Santoro N, Lo Y, Moskaleva G, et al. Factors affecting reproductive hormones in HIV-infected, substance-using middle-aged women. Menopause. 2007; 14:859-865. [PubMed: 17415019] 
87. Su, HI.; Alton, J.; Sherman, L.; Stankiewicz, C.; Ratcliffe, S.; DeMichele, A. Relationships between clinical and biochemical predictors of chemotherapy related amenorrhea in premenopausal adjuvant breast cancer patients. American Society of Clinical Oncology Annual Meeting Proceedings, Part 12007; p. 11011

88. Su HI, Sammel MD, Velders L, et al. Association of cyclophosphamide drug-metabolizing enzyme polymorphisms and chemotherapy-related ovarian failure in breast cancer survivors. Fertil Steril. 2009; 94:645-654. [PubMed: 19376514]

89. Sukumvanich P, Case LD, Van Zee K, et al. Incidence and time course of bleeding after long-term amenorrhea after breast cancer treatment: a prospective study. Cancer. 2010; 116:3102-3111. [PubMed: 20564648]

90. Welt CK, Pagan YL, Smith PC, Rado KB, Hall JE. Control of follicle-stimulating hormone by estradiol and the inhibins: critical role of estradiol at the hypothalamus during the luteal-follicular transition. J Clin Endocrinol Metab. 2003; 88:1766-1771. [PubMed: 12679471]

\section{APPENDIX}

\section{STRAW + 10 Program Committee}

Siobán D. Harlow, PhD, Program Chair, Professor, Department of Epidemiology, University of Michigan

Margery Gass, MD, NCMP, Executive Director, The North American Menopause Society

Janet E. Hall, MD, President, The Endocrine Society; Professor, Department of Medicine, Harvard Medical School

Roger Lobo, MD, President, American Society of Reproductive Medicine, Professor, Department of Obstetrics and Gynecology, Columbia University

Pauline Maki, PhD, Professor, Departments of Psychiatry and Psychology, University of Illinois

Robert W. Rebar, MD, Executive Director, American Society for Reproductive Medicine

Sherry Sherman, PhD, National Institute on Aging

Tobie J. de Villiers, MBChB, FRCOG, FCOG(SA), President, International Menopause Society (South Africa)

\section{STRAW + 10 Collaborative Group}

Susan E. Appt, DVM, Wake Forest School of Medicine (United States); Valerie L. Baker, MD, Stanford University (United States); Frank J. Broekmans, MD, PhD, University Medical Center Utrecht (Netherlands); Marcelle I. Cedars, MD, Ruth Greenblatt, MD, University of California at San Francisco (United States); Sybil Crawford, PhD, Lynnette L. Sievert, PhD, University of Massachusetts (United States); Lorraine Dennerstein, MD, University of Melbourne (Australia); Ellen W. Freeman, PhD, Mary Sammel, ScD, University of Pennsylvania (United States); Marjorie Gass, MD, NCMP, The North American Menopause Society (United States); Georgina Hale, MD, PhD, University of Sydney (Australia); Janet E. Hall, MD, Harvard Medical School (United States); Karl R. Hansen, MD, PhD, University of Oklahoma (United States); Siobán D. Harlow, PhD, Rod Little, PhD, Pangaja Paramsothy, MPH, John F. Randolph, MD, University of Michigan (United States); Nicole Jaff, NCMP, PhD, Research Fellow, University of the Witwatersrand (South Africa) Hadine Joffe, MD MSc, Jan Shifren, MD, Patrick M. Sluss, PhD, Massachusetts General Hospital (United States); Roger Lobo, MD, Michelle Warren, MD, 
Columbia University (United States); Pauline Maki, PhD, Professor, University of Illinois (United States); Kathleen O'Connor, PhD, Nancy Fugate Woods, RN, PhD, University of Washington (United States); Robert Rebar, MD, American Society for Reproductive Medicine (United States); Gloria Richard-Davis, MD, Meharry Medical College (United States); David M. Robertson PhD, Prince Henry's Institute of Medical Research, Monash University (Australia); Sherry Sherman, PhD, National Institute on Aging (United States); Claudio N. Soares, MD, PhD, McMaster University (Canada); H. Irene Su, MD., University of California at San Diego (United States); Josefina Romaguera, MD, MPH, University of Puerto Rico (Puerto Rico); Wulf Utian, MD, Case Western Reserve School of Medicine (United States); Heidi VandenBrink, University of Saskatchewan (Canada); Tobie J. de Villiers, MBChB, FRCOG, FCOG (SA), International Menopause Society (South Africa); Miriam T. Weber, PhD, University of Rochester (United States); Melissa F. Wellons, MD, University of Alabama (United States). 


\section{SUMMARY}

STRAW + 10 simplified bleeding criteria for the early and late menopausal transition, recommended modifications to criteria for the late reproductive and the early postmenopause stages, provided information on the duration of the late transition and early postmenopause, and recommended application regardless of women's age, ethnicity, body size, or lifestyle characteristics. Seven research priorities are identified. 


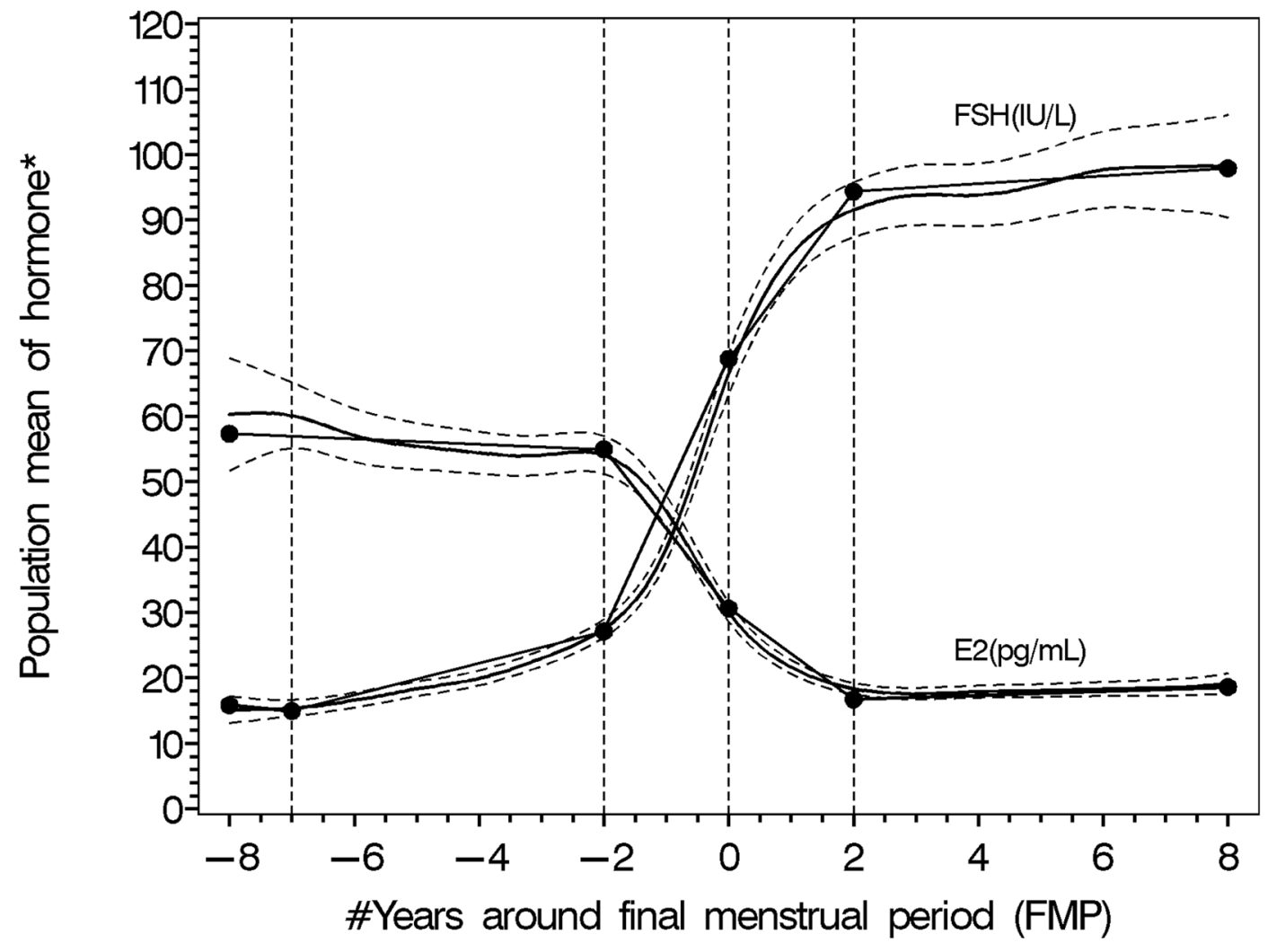

FIG. 1.

Adjusted population means (95\% CI) for segmented mean profiles follicle-stimulating hormone and estradiol across the final menstrual period in the Study of Women's Health Across the Nation $(\mathrm{N}=1,215)$. *The $y$ axis is unitless. The units of hormone are marked in the corresponding curves. Reproduced with permission from Randolph et al, JClin Endocrinol Metab 2011;96:746-754. 


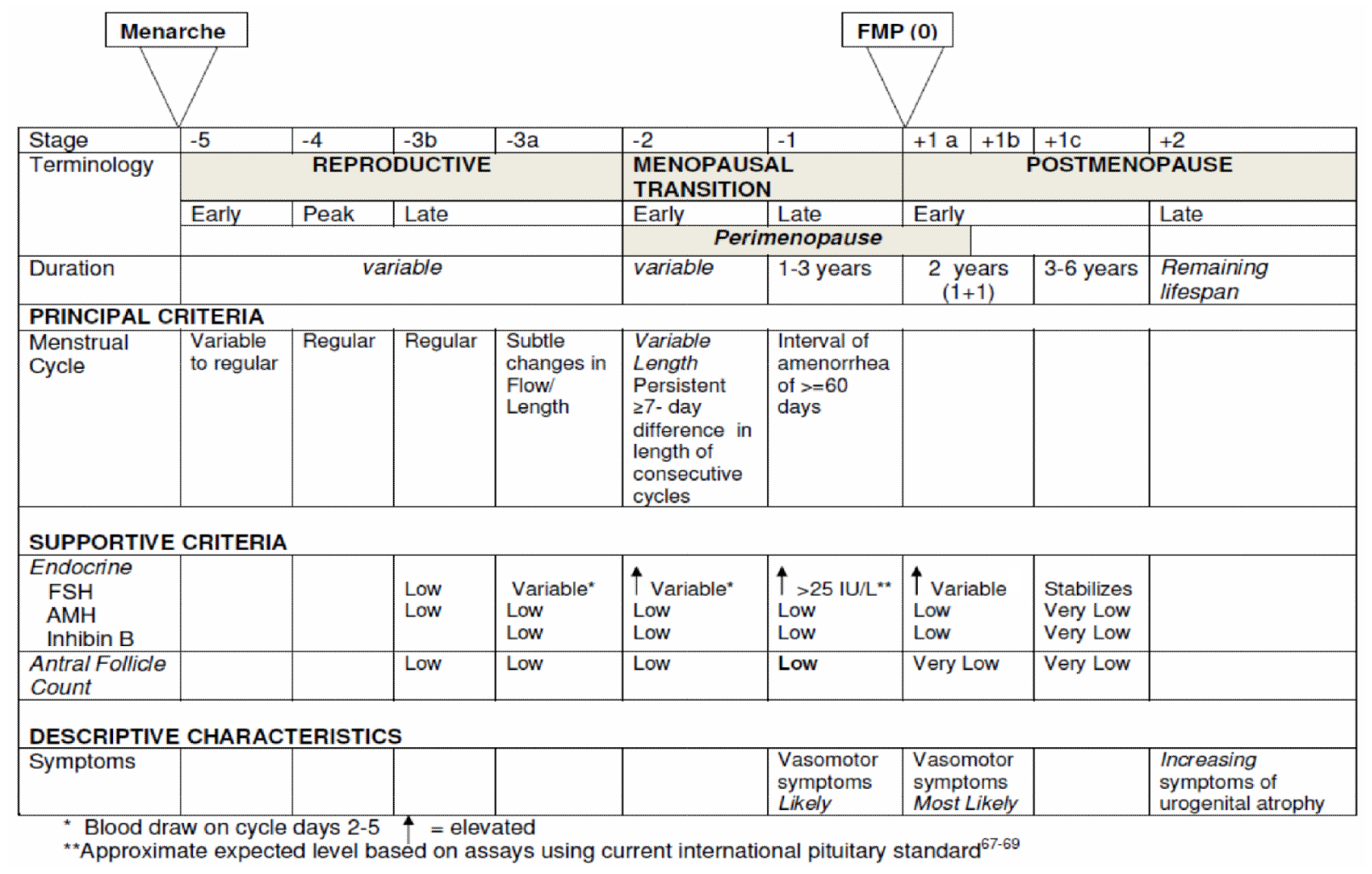

FIG. 2.

The Stages of Reproductive Aging Workshop + 10 staging system for reproductive aging in women. 